\title{
REFLECTIONS
}

\section{The Staging of Menopause}

Behram S Anklesaria

\begin{abstract}
Staging of menopause not published and needed to be defined for long-term consequences and their management. This staging based on duration, event and action seems to be relevant. Each stage duration is highly variable, but a rough 5 years per stage calculation is clinically us eful. Our 'staging of menopause' has now become the best method to understand the symptomatology, the complications and the management of a woman's best years - the menopause!
\end{abstract}

Keywords: Menopause, Staging, Symptomatology.

How to cite this article: Anklesaria BS. The Staging of Menopause. J South Asian Feder Menopause Soc 2013;1(1): $1-3$.

\section{Source of support Nil}

Conflict of interest: None declared

\section{INTRODUCTION}

Modern menopause management is a subject that has interested Indian physicians to an ever-increasing extent since the last 3 decades. Ever since my earliest involvement with Indian M enopause Society (IM S), I was troubled by the fact that no staging system for menopause was published anywhere in the world. I found this strange, because it was obvious to me that the clinical events occurring in a woman's life around the time of menopause are progressive endocrinological changes. In the first staging system ever published (1997), I divided the menopause transition into three stages, each with a duration line, an events line and an action line. This article deals with the relevance of my staging system in modern times, 14 years after its first publication. $^{1}$

\section{STAGES OF MENOPAUSE}

\section{Stage I}

From the earliest perimenopausal symptom (usually vasomotor instability or menstrual irregularity) to menstrual cessation (menopause).

\section{Stage II}

Five years after menopause.

\section{Stage IIA}

From the cessation of menstruation up to 1 year (that is up to confirmation of menopause by WHO definition). The main symptoms of menopause during this stage are urethral syndrome and vasomotor instability.

Staging of menopause, Dr Behram S A nklesaria (1997)

\begin{tabular}{|c|c|c|c|c|c|}
\hline Stages & Stage I & & Stage IIA & Stage IIB & Stage III \\
\hline Y ears & $\begin{array}{l}\text { Roughly } 3-5 \text { years before } \\
\text { the menopause }\end{array}$ & & One year & $\begin{array}{l}\text { Up to } 5 \text { years } \\
\text { after the menopause }\end{array}$ & $\begin{array}{l}\text { From } 5 \text { years } \\
\text { after menopause up to her } \\
\text { lifetime }\end{array}$ \\
\hline \multirow[t]{12}{*}{ Events } & \multirow[t]{2}{*}{ IA : M enstrual irregularity } & M & C & \multirow{4}{*}{$\begin{array}{l}\text { Local atrophic } \\
\text { changes } \\
\text { Late psychosomatic } \\
\text { symptoms }\end{array}$} & III A: L ate atrophic changes \\
\hline & & E & 0 & & III B: Ischemic heart disease \\
\hline & \multirow[t]{2}{*}{ IB : V asomotor instability } & N & $\mathrm{N}$ & & III C: Osteoporosis \\
\hline & & 0 & $\mathrm{~F}$ & & \\
\hline & \multirow{8}{*}{$\begin{array}{l}\text { IC: Early psychosomatic } \\
\text { symptoms }\end{array}$} & $P$ & I & & III D: V ery late \\
\hline & & $A$ & $\mathrm{R}$ & & complications, e.g. cerebro- \\
\hline & & U & $M$ & & vascular accidents, \\
\hline & & S & $A$ & & A lzheimer's disease, etc. \\
\hline & & $E$ & $\mathrm{~T}$ & & \\
\hline & & & । & & \\
\hline & & & 0 & & \\
\hline & & & $\mathrm{N}$ & & \\
\hline Action & Establish communication & & & Treat & Prevent \\
\hline
\end{tabular}


Stage IIB

From end of II A up to 4 years. The usual symptoms are as follows:

- A trophic symptoms, vaginitis, dyspareunia

- Urinary symptoms

- Weight gain + abnormal weight distribution

- Skin and hair changes

- Genital prolapse

- Late psychologic symptoms

- Sexual disorders.

\section{Stage III}

From 5 years after menopause up to her lifetime.

- III A: Late atrophic changes

- III B: Ischemic heart disease

- III C: Osteoporosis

- III D: Very late complications, e.g. cerebrovascular accidents, Alzheimer's disease, etc.

\section{PRACTICAL USAGE}

\section{The 5-Year Rule of Thumb}

- Each stage duration is highly variable, but a rough 5 -years per stage calculation is clinically useful.

- Consider the case of lady 'A' who reaches her menopause at say age 50 .

- From 45 to 50 years, she is in stage I when she needs initial counseling.
- From 50 to 55 years, she will be in stage II- the window of opportunity.

- From 55 to 70 years, she will go through the earlier stages III complications which could have been prevented.

- At 70t, she enters stage III D and beyond. She now needs very different management than the earlier stages.

In 1997, when this staging system was first published, long-term hormone replacement therapy (HRT) was popular in the W est. Subsequently, this staging has been widely published in India and abroad. In 2008, it was adopted by the IM $S$ and presented at the W orld Conference of the International M enopause Society at M adrid. ${ }^{2}$

M eanwhile, WHO and other studies considerably reduced the popularity of long-term HRT. However, our staging system has now become even more relevant because HRT and other interventions are now critically time bound. For example, the window of opportunity period for initiation of long-term HRT corresponds with 'Stage II' of this system.

Individualized management of $40+$ women with their diverse cultural and regional needs is not possible without clinical categorization.

Individualization of treatment involves another more important aspect. The same patient develops different needs at various 'stages' of menopause. A good physician will encourage the patient to report regularly and will alter the management to suit her ever-changing needs. This simple

\begin{tabular}{|c|c|c|c|c|c|c|}
\hline \multicolumn{7}{|c|}{$\begin{array}{c}\text { STRAW System } \\
\text { (Stages of Reproductive Aging Workshop) }\end{array}$} \\
\hline \multicolumn{7}{|c|}{ The early climacteric years } \\
\hline \multicolumn{7}{|c|}{ Signs and symptoms } \\
\hline & & Flushes & Night swe & reats & & \\
\hline Fertility & \multicolumn{2}{|c|}{ Menstrual cycle problems } & & & & \\
\hline \multirow[t]{3}{*}{ Contraception } & \multicolumn{2}{|c|}{ Uterine bleeding } & & & & \\
\hline & \multicolumn{2}{|l|}{ PMS } & \multicolumn{3}{|c|}{ Breast carcinoma } & \\
\hline & \multicolumn{6}{|c|}{ Final menstrual period (FMP) } \\
\hline \multirow{4}{*}{$\begin{array}{r}\text { Stages: } \\
\text { Terminology: }\end{array}$} & -2 & -1 & & & 1 & 2 \\
\hline & \multicolumn{3}{|c|}{ Menopausal transition } & & \multicolumn{2}{|c|}{ Postmenopausal transition } \\
\hline & Early & & -ate & & Early & Late \\
\hline & \multicolumn{4}{|c|}{ Perimenopause } & & \\
\hline Duration of stages: & \multicolumn{3}{|c|}{ Variable } & $\begin{array}{l}\text { (a) } \\
1 \mathrm{yr}\end{array}$ & $\begin{array}{l}\text { (a) } \\
4 \text { yrs }\end{array}$ & Until demise \\
\hline Menstrual cycles: & $\begin{array}{l}\text { Variable cycle length } \\
\text { (>7 days different } \\
\text { from normal) }\end{array}$ & \multicolumn{2}{|c|}{$\begin{array}{c}\text { 2 skipped cycles and } \\
\text { an interval of } \\
\text { amenorrhea ( } \geq 60 \text { days) }\end{array}$} & & \multicolumn{2}{|c|}{ None } \\
\hline Endocrine: & \multicolumn{3}{|c|}{$\uparrow \mathrm{FSH}$} & & \multicolumn{2}{|c|}{$\uparrow \mathrm{FSH}$} \\
\hline
\end{tabular}

FSH: Follicle stimulating hormone 
scientific 'staging system', widely disseminated, has helped us to do just that.

We have just detailed the Anklesaria staging system, published in 1997. The author presents here his staging system, first published in India in 1997. Four years later in 2001, the 'Stages of Reproductive A geing W orkshop (STRAW) and the A merican Society for Reproductive Medicine published another staging system. ${ }^{3}$ This is an excellent system for reproductive aging, useful for managing infertility problems of older women. However, in dealing with symptomatic and preventive aspects of menopause, we feel that our ol der staging system is superior. It has been widely propagated in textbook chapters, journals and through lecturers all over the world. ${ }^{4,5}$

Some interesting facts emerge on comparison between the two-staging systems. The STRAW system details the premenopaused stage with an emphasis on the fertility aspects. However, there is no action line and no emphasis on the prevention of menopause complications. On the contrary the A nklesaria staging system mentions no aspects of fertility in the 'first stage' but goes to great lengths in enumerating the progressive complications in the 'third stage.' The last line clearly emphasizes the action philosophy at each stage with 'preventing complications' in the third stage.

\section{CONCLUSION}

The most important sociomedical change of the present era has been the dramatic increase in life expectancy and the dramatic rise of older populations, woman's liberalization, emancipation and professionalism has led to spreading concepts of menopause as a 'positive' change, greatly encouraging is the rising awareness of the benefits of life style changes. Estrogen therapy for treatment and prevention has become complicated. However, the most important development has been the crucial importance of the timing of various interventions in menopause management. That is why our 'staging of menopause' has now become the best method to understand the symptomatology, the complications and the management of a woman's best years - the menopause!

\section{REFERENCES}

1. A nkesaria BS. HRT for mature women using a clinical staging system. Gujarat M edical J ournal 1997;54:685-89.

2. A nkesaria BS. Staging of menopause: The Indian mantra. Proceedings of the International M enopause Society Conference, M adrid 2008, M aturitas 2009.

3. Executive Summary: Stages of R eproductive A geing W orkshop (STRA W) M enopause 2001;8:402-07.

4. A nkesaria BS, Soneji R M. Risk-benefit balance in management of menopause. In: Purandare CN, K hadilkan SS (Eds). M enopause: Current Concepts. New Delhi, India: Jaypee B rothers M edical Publishers 2004;194-205.

5. Kumar P, Malhotra N. M enopause. In: J effcoate's (7th International ed). New Delhi, India: Jaypee Brothers M edical Publishers 2008;862-63.

\section{ABOUT THE AUTHOR}

\section{Behram S Anklesaria}

Senior Consultant, Obstetrician Gynecologist, Special ist in Infertility, Endoscopy, M enopause and A dolescence, DrSB A nklesaria H ospital for Women Lal Darwaja, A hmedabad, Gujarat, India, Founder President, South A sian Federation of M enopause Societies (SAFOM S) Chairman, Indian College of Obstetrics and Gynecology (ICOG) (2010-12); Past President, Federation of Gynecological and Obstetric Societies of India (FOGSI) and Indian M enopause Society (IM S) Professor, Emeritus and Chairman, Ethics Committee, N HL Medical College and LG Hospital, A hmedabad, Gujarat, India Phone: +919825011000, e-mail: me40no.pause@gmail.com 